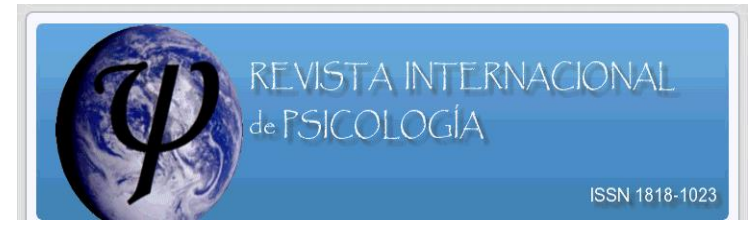

\title{
INTERPRETACIÓN Y ESCENA ANALÍTICA
}

\author{
Dra. Patricia Cordella ${ }^{1}$
}

\section{¿Cómo ocurre la interpretación?}

La interpretación es como un salto, una apertura, la estructura de un agujero que late. Es un acto que opera en el sentido, en el saber del inconsciente. La interpretación aparece como efecto de corte en la continuidad especular del yo, la sorpresa de advenir, el des-velo, el insostenible límite donde la verdad ciega , donde es mejor volver a construir, para huir, un fantasma. La interpretación es como el modo de entrar en el permanente y rítmico movimiento del inconsciente, es una variable en variación, una variable fugitiva.

Esta variable que intenta asir la interpretación, no cesa de escaparse y de aparecer. Aparece en el advenir, bajo falla, error, repitencia ( síntoma) del sujeto: No respeta el tiempo, situándose en todos los tiempos, no sabe de espacios , ni posiciones, vagabundeando hasta el infinito, encuentra el sentido para perderlo.

Esta variable transgrede el orden cotidiano a través del significante, es una especie de puerta discursiva que se abre para re-vertir, sub-vertir ,con-vertir . Entonces la interpretación surge como una acción y efecto de lengua a lengua. Concebida bajo autorización de cierto mandato de ese cierto sujeto que fundó la técnica. La Interpretación opera como instrumento de corte, como traducción o sentencia .

La interpretación : ¿un acto, un pacto , un rapto, un lapso? La interpretación en transferencia es por fundación como una vuelta de intención rota, una vuelta fallida a la repetición. Una desmentida, un agitar de sedimentos, allá en el fundamento . Un confundir lo que es y lo que es expulsado a la vez. La coreografía en el límite de lo cierto y lo incierto, en el lugar- tiempo de la verdad.

\footnotetext{
${ }^{1}$ Pontifica Universidad Católica de Chile. Correo electrónico: cordella@ caschile.cl
} 


\section{¿Qué podemos decir del acto de interpretar?}

Como vemos en el cuadro adjunto la propuesta de análisis en la problemática de la interpretación sitúa en la escena a varios significantes en relación : el inconsciente, el espacio, el tiempo, el sujeto, el analista, la verdad, el saber, la transferencia, el mandato y la ética del acto analítico entre otras distinciones ( diferencias). En fin o en principio, uno va enlazado a otro , hay continuos, donde uno es lo otro. En esta oportunidad nos moveremos en tres ejes que enunciaremos como parte de la problemática:
a.
El Mandato del analista
b. La noción de tiempo
c. La noción de verdad

\section{El Mandato del analista}

"Wo es war soll ich werden" traducido como "donde Ello era, yo debo advenir" se posiciona en el campo de la ética del psicoanálisis. Este sería el mandato del analista.'WO" habla de un tiempo y un lugar inespecífico donde se advendría, donde ? Cuando?

"ES" se refiere a "eso" algo anterior a la definición del género; indefinible, posible de ser amputado de pronombre ya que no es yo, no es tu, no es nosotros, no es ella, es “ello". Además es de causa indeterminada, no tiene participación en el presente y las sensaciones que presenta son independientes del sujeto.

Nos quedamos entonces con un "eso" o un "ello" mas cercano al cuerpo que al discurso y que sin embargo adviene en la palabra ."Ello" es enigmático $i$ por esencia, presencia o ausencia ?. Luego viene el "WAR" lo que "fue o estuvo" aludiendo tanto a un permanente (ente) como a un proceso que fue.

El "SOLL" es quien lleva el imperativo, el mandamiento, el fundamento del acto. El contrato, el legado del fundador . El "ICH" es "yo", el que dice el enunciado , ¿quien dice "yo" ? el padre del psicoanálisis o cualquiera de sus discípulos? Tal vez el propio 
paciente puede ser el sujeto que estima ético llegara a encontrarse con su verdad y acude a análisis.

Luego el "WERDEN" que traducido como advenir no deja de incluir el crear, desarrollar, devenir, nacer, surgir, volverse algo. Aludiendo a una instancia que será producida. O desde el cambiar, transformar, degenerar, constituir, erigirse , aluden a algo que estaba o era y que mutará, un cambio de algo por algo. También puede ser un auxiliar como algo que acompaña pero no determina, en cierta función pasiva. Una traducción libre al mandato podría ser propuesta como “ En algún lugar y tiempo ( el espacio de todos los espacios y el tiempo de todos los tiempos. Cuadro anexo) sucedió ( algo que fue o estuvo) eso y debe o ha de repetirse para re-crearse.

El mandato parece decir que algo se ha perdido, que hay una falta, que no es posible olvidar la falta, que la memoria es olvido y que en este rescate del significante excluido hay algo muy importante del orden de lo innombrable, pero posible de real-izar, es decir de volver a "erigir" desde lo real. Algo que no es sustancia ni materia y que sin embargo es esencial. El mandato parece decir que lo nunca sido se recuerda y que es indestructible a pesar de no estar disponible y de ser un efecto de la articulación entre el sujeto y "eso".

El inconsciente es el puente a través del cual llegamos justo antes que se cierre la boca del deseo en "eso". Llegamos por su insistencia, por la insatisfacción que lo define, por el latido incesante y ubicuo. La palabra y sus cortes llegan donde hay silencio.

\section{La noción de tiempo}

La cuestión del tiempo toma relieve cuando al entender el inconsciente, como ónticamente evasivo "no es ser ni no ser sino el orden de lo no realizado", pretendemos articularlo en el instante, la fugacidad, el momento, cazarlo en la estructura del tiempo. En un deseo de hacer de la cosa un perdurable, una duración de la sustancia. Como si el deseo inderogable se sometiera a hipostasis. El tiempo cronológico es útil al acuerdo, al concite social, pero poco tiene que ver con "eso" que no conoce el tiempo, en "lo ya sido", en el infinitivo que es presente recién transitado, momento elusivo. El tiempo verbal de "eso" será un tiempo de varios tiempos, inconocible, no concluyente, 
articulado incluso con enlaces falsos, pero lógicos. Entonces dirá Lacan hay tiempos de a-proiri(anticipación), hay tiempos de a-posteriori ( retroacción) y tiempos lógicos.

La lógica, la articulación, los enlaces ( falsos o verdaderos) se apoyarán en el tiempo y abandonarán la intemporalidad a la que estaban relegadas. El cruce de la lógica con el tiempo se hará en tres tiempos: 1-veo; 2-comprendo;3-concluyo. La tensión entre sostener la incertidumbre y precipitarse en la urgencia de la certidumbre permitiría resolver el sofisma de los prisioneros ( Lacan Escritos 1. El aserto del tiempo lógico)así como permitiría regular la interacción humana en un tiempo que es mas subjetivo que cronológico. El significante, por otra parte, terminará rodando en la línea temporal de la metonimia y ajustándose en algún paradigma atemporal. También el tiempo será visto como movimiento estructural en saltos, como sucede en los tiempos del Edipo, que no es momento diacrónico sino un tiempo sincrónico .

El tiempo actuando como un electrón que salta de órbita, adelante, atrás , va y vuelve está y vuelve . Vuelve ¿donde? ¿Qué vuelve? ¿Hay posición para el tiempo? ¿ hay verdad en la palabra temporizada? ¿Se trata de tiempos de aperturas y cierres? ¿ de ausencias y presencias? ¿todo sería un fort-da hablado? Un juego en que lo que fue se trae para volver a ser? ¿Un reclamo de presencia? ¿Somos recomponedores? Si cada vez se reincribe, se reorganiza, se constela, si la anticipación es el efecto del futuro en el presente ¿Hay presente-puro? Si la retroacción es el efecto del presente en el pasado ¿ hay pasado-puro? La lógica quiere zambullirse en la conclusión ,rodar desde la anticipación a la certidumbre futura.

Podemos decir con Freud que nada hay en el inconsciente que responda a la idea convencional de tiempo. El tiempo no pasa, no circula, no hay huella mnémica fechada, hay descomposición espectral, disponibilidad del fragmento mnémico . El tiempo se hace tiempo en el corte, el borde, el momento del cierre del inconsciente en el momento catastrófico en que la subjetividad concluye. Sucede el tiempo del acontecimiento bajo transferencia, el acercarse a la angustia primaria, a la inmediatez de lo real, el lugar del desconocimiento para hacer de la letra lo real de lo simbólico y poder trabajar el prohibido goce.

Como si un salto quisiera alcanzar el fundamento o la nada que es presente reiterado en relación con la muerte o mas allá de ello. Así no hay tiempo donde se 
encuentre el sujeto con el objeto, no hay un punto permanente que de cuenta de un estar, sino hay un eterno errar en reversa y anversa que produce "esas olas". La interpretación entonces, pensada a través de la noción de tiempo se presenta como un proceso dis-continuo, inmediato, i- lógico, enigmático, inexacto, . Un intento de modificar la perseverancia del volver sobre sí, subvirtiendo incluso el orden del tiempo en un paso sin puerta.

\section{La noción de verdad}

Lo real y lo verdadero no son sinónimos . O sea la interpretación no es la operación de calce entre ellos? ¿No se trata o con-trata a un traductor de lo real? A un baqueano del centro de algún logos? Algunos habrán creído en la exégesis de lo real mientras el sujeto sabe que la verdad está en él aunque no pueda abrir la boca para decir sino a medias, porque "la verdad, no toda". Será posible que la verdad, toda la verdad y nada mas que la verdad cure de verdad? ( Braunstein 1999) aún sabiendo que la verdad solo a medias puede decirse? Y mas aún ,sabiendo que se puede llegar a ella desde premisas falsas? Y que además, el inconsciente ,tiende a mentir sobre "el mal" ( sexualidad) ? ¿Como acercarnos a la verdad si verdadero puede ser sinónimo de falso ? Posicionar un saber en el lugar de la verdad tendría la función de informar al sujeto que no sabe, sabiendo, es decir le daría significación y sentido a los sonidos que de él emanan . ¿Qué consistencia podría tener un quehacer que se presenta así de contradictorio? O será necesario ir mas allá de las fronteras lógicas para obtener "el efecto" de la interpretación?

Zanjar la verdad o falsedad de una proposición pudiera cerrar la red de significantes, instituir a un sistema formal. Allí podríamos crear consistencia, completud. Hacer de la fórmula algo demostrable y decible. El procedimiento sería igual para todos a la hora de la demostración, de la supuesta verdad . Estaríamos hablando de ciencia, garantía de verdad, de modernismo. El pensamiento matemático en su afán de buscar "esa verdad acerca de las cosas" falla como nos lo comunica Godel ( Hosfstadter 1987)pues no es posible incluir todas las proposiciones de un sistema formal dentro del mismo sistema. Nunca un significante podrá significarse a sí mismo según supimos en las paradojas ( como la del barbero) de Russell y Whitaker. La noción formal de verdad necesariamente requiere de un conjunto vacío . Un conjunto 
que esté fuera ( Vegh 1999) que inscriba la falta, que instituya la castración simbólica. Que deje el falo como el símbolo imposible de negativizar. Esta falta será la condición del deseo y la constitución del sujeto.

El objeto "a" causa del deseo tiene como condición faltar para ser operante. De este modo la verdad sucedería dentro de un sistema castrado. El acto analítico presentificaría lo real, a través del fantasma. Los cruces entre los registros imaginarios simbolico y real darían garantía de la Cosa. Y sin embargo, no hay consistencia que garantice la existencia ni la verdad ,así sea que la articulación de sus nociones se realice rigurosamente y el lugar de la verdad sea aspirar a lo real . Lo real como lo indecible, lo que fastidia, e incomoda, el saber imposible que surge como error o traspiés tiene una relación con la verdad y esta con el sujeto, pero ¿qué clase de relación? Una de ocultamiento, de des-vío, de velamiento, de ambigüedad, de conexión o desconexión entre significantes.

Una relación de subordinación del sujeto al significante, afectado de inconsciente, que a su vez es algo en lo real. Una relación de bordes de distinción, de abismos .El lugar de la verdad es demarcado por el saber del inconsciente, función de lo real. El inconsciente como espectro o fantasma a su vez de lo real ,se expresa en formaciones, sistemas de "tiro y retiro" que insisten en lo esencial así sea que nadie lo entienda. Saber y verdad vuelven a aparecer como dos lados de la banda de Moebius (Hahari 1999). A veces saber inconsciente que habla de la verdad del deseo y otras, verdad que se expresa en el equivoco o el síntoma. La verdad aparece en el habla delatando un corte, una represión original. Es en la ciencia donde saber y verdad se articulan.

En psicoanálisis la verdad es la causa que determina el movimiento, el acto, no es un demostrable, ni la certeza de la representación, por ser palabra de oráculo, ambigua y oscura, un enigma en tanto formación contradictoria de una imposibilidad racional. El saber aparece como un efecto de la operación significante con el cual el sujeto se tropieza y desconcierta. Y ¿qué sabe cuando sabe? ¿del goce ?, ¿La referencia a la castración ? Tal vez, la verdad es un efecto binario de valor variable en relación a la posición que el sujeto ocupe con respecto a la pulsión. La verdad sería una artrología y no el calce exacto entre lo simbólico y lo real. Tampoco el trauma en cuanto 
realidad fáctica, sino, por el contrario la discordancia que provoca el retorno de lo que quedó reprimido, expulsado, forcluido en la pretendida adecuación.

\section{Conclusión}

Se presenta una discusión de la interpretación tomando en cuenta tres de los ejes presentes en la escena analítica cuando opera como artefacto de la técnica. La interpretación se grafica con mas elementos que los discutidos, tomando en cuenta que esta discrecionalidad es solo a modo de análisis porque una y otra variable forman parte de un mismo dominio continuo : el dominio de la existencia que se juega en el acto analítico a través de un mandato ético. Este mandato ético es jugar con la verdad del sujeto, verdad que se muestra y oculta como un latido entre lo lleno y lo vacío, entre el sonido y el silencio, entre el flujo y el corte . La dinámica de la interpretación se juega en la dinámica de varios ejes. Aquí discutimos algunos de ellos.

\section{Bibliografía}

1. Braunstein Psiquiatría teoría del sujeto, psicoanálisis (hacia Lacan) Siglo XXI ,1999

2. Dor, Jintroducción a la lectura de Lacan Gedisa 1986

3. Dylan Evans Diccionario Introductorio de psicoanálisis lacaniano Paidos1997

4. Lacan, j . Escritos 1 . El Tiempo lógico y el aserto de la certidumbre anticipada. Un nuevo sofisma.. Siglo XXI 2001

5. Vegh,I Los discursos de la cura Wainstein Acme agalma 1999

6. Vegh,I matices del psicoanálisis agalma 1991

7. Nasio J,D Los gritos del cuerpo Paidos 1996 
8. Harari, R Los cuatro conceptos fundamentales del psicoanálisis de Lacan: una introducción . Nueva visión1999

9. Ogilvie ,B Lacan la formación del concepto de sujeto Ed Nueva Visión 2000

10. Posada, P . Saber y verdad . Revista de la universidad de Antoquia enero 1999

11. Hosfstadter,D Godel, Escher , Bach . Libros para pensar la ciencia 1987

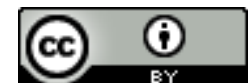

Este texto está protegido por una licencia CreativeCommons 4.0.

Usted es libre para Compartir — copiar y redistribuir el material en cualquier medio o formato - y Adaptar el documen- to - remezclar, transformar y crear a partir del material- para cualquier propósito, incluso comercialmente, siempre que cumpla la condición de:

Atribución: Usted debe reconocer el crédito de una obra de manera adecuada, proporcionar un enlace a la licencia, e in- dicar si se han realizado cambios. Puede hacerlo en cualquier forma razonable, pero no de forma tal que sugiera que tie- ne el apoyo del licenciante o lo recibe por el uso que hace. 